\title{
Fostering social change among advantaged and disadvantaged group members: Integrating intergroup contact and social identity perspectives on collective action
}

Group Processes \& Intergroup Relations

\author{
Gian Antonio Di Bernardo, ${ }^{(1 D}$ Loris Vezzali, ${ }^{(1 D}$ Sofia Stathi, ${ }^{2}$ (D) \\ Shelley McKeown Jones, ${ }^{3}$ Veronica Margherita Cocco, ${ }^{1}$ \\ Tamar Saguy ${ }^{4}$ and John Dixon ${ }^{5}$
}

\begin{abstract}
Recent research on intergroup contact has shown how interactions with outgroup members may both decrease and increase motivations to achieve social equality. Similarly, social identity theory has identified the conditions that lead individuals to challenge unequal social systems. Integrating these two major theories, the current study examined the processes underlying the relationship between intergroup contact and participants' willingness to engage in collective action to challenge social inequality. Specifically, we tested sociostructural variables (status legitimacy and stability, and permeability of group boundaries) as potential mediators of contact in a sample of both advantaged (Italian high school students, $N=392$ ) and disadvantaged (immigrant high school students, $N=165$ ) group members. We found that contact was positively associated with motivation for change, an effect mediated by decreased perceived legitimacy of status differences. Moreover, for the advantaged group, membership salience moderated the effects of quality (but not quantity) of contact. Indirect effects were instead not moderated by content of contact (an index considering the extent to which contact was characterized by a focus on differences vs. commonalities between groups). Theoretical and practical implications of findings are discussed.
\end{abstract}

\section{Keywords}

collective action, intergroup contact, membership salience, social change motivation, social identity theory

Paper received 17 September 2018; revised version accepted 28 October 2019.

\footnotetext{
${ }^{1}$ University of Modena and Reggio Emilia, Italy

${ }^{2}$ University of Greenwich, UK

${ }^{3}$ University of Bristol, UK

${ }^{4}$ Interdisciplinary Center Herzliya, Israel

${ }^{5}$ The Open University, UK
}

\author{
Corresponding author: \\ Gian Antonio Di Bernardo, Department of Education and \\ Human Sciences, University of Modena and Reggio Emilia, \\ Viale Allegri 9, Reggio Emilia 42121, Italy. \\ Email: gdibernardo81@yahoo.com
}


Social psychologists have traditionally sought to develop interventions to produce positive outgroup attitudes, reduce intergroup conflict, and promote equality between groups. Intergroup contact is often portrayed as one of the most effective strategies for reducing prejudice and producing a more equal society. The meta-analysis by Pettigrew and Tropp (2006) and other extensive reviews (e.g., Hodson \& Hewstone, 2013; Pettigrew \& Tropp, 2011) have demonstrated that higher levels of contact are typically associated with lower levels of prejudice. In so far as prejudice is one of the key determinants of discrimination, intergroup contact may be a central driver of social change in historically unequal societies.

However, recent research casts some doubts on the usefulness of contact in promoting intergroup equality (Dixon, 2017; Wright \& Lubensky, 2009). There is emerging evidence that positive contact may inhibit support for action toward social change among members of both advantaged and disadvantaged groups (Saguy, 2018; Saguy, Shchory-Eyal, Hasan-Aslih, Sobol, \& Dovidio, 2017). At the same time, however, there is also evidence that contact is associated with positive societal outcomes including civic engagement (McKeown \& Taylor, 2017) and increased support for ingroup rights amongst both disadvantaged (Kauff, Green, Schmid, Hewstone, \& Christ, 2016) and advantaged groups (Vezzali \& Giovannini, 2011). Thus, existing research provides mixed results on the association between contact and social change.

In the current research, we aim to investigate this issue further by overcoming several limitations in past work. Existing research has typically examined the association between contact and social change among advantaged and disadvantaged groups separately. This separate focus limits the ability to compare across the groups and also to provide a joint theoretical rationale that would be relevant for both. Specifically, in the context of collective action, contact research has not sufficiently been integrated with major intergroup theories of social change, such as social identity theory (SIT; Tajfel \& Turner, 1979). We argue that considering whether or not contact effects are driven by processes underlying collective action as identified by SIT can be critical in developing a fuller understanding of contact effects and of the way they might operate differently, or similarly, among advantaged and disadvantaged groups.

Thus, in the current research we integrated intergroup contact theory and social identity theory (Tajfel \& Turner, 1979) to examine the processes that underly the association between contact and social change among both advantaged and disadvantaged group members. More specifically, our study operationalized variables derived from both SIT and contact theory that, though relevant to understanding social change, have commonly been considered independently. In particular, drawing on SIT, we investigated if the perceived legitimacy and stability of status differences and permeability of group boundaries mediate the association between contact and motivation for social change. As a secondary aim, we also explored whether the salience of group membership during contact (Brown \& Hewstone, 2005) and the content of the contact (focused on differences vs. commonalities; Vezzali, Andrighetto, Capozza, Di Bernardo, \& Saguy, 2017) moderate the association between contact and social change, and the predicted indirect effects.

\section{Intergroup Contact and Social Change}

The literature on intergroup contact has mainly focused on its effectiveness in reducing prejudice among advantaged group members, providing consistent evidence that positive interactions with outgroup members can improve intergroup relations (Hodson \& Hewstone, 2013). Surprisingly, until comparatively recently, the relation between contact and broader forms of social change has been relatively underinvestigated. Emerging research on this topic has raised concerns about the potential limits of the contact hypothesis both when considering advantaged and disadvantaged group members' tendencies to promote social change (e.g., Becker, Wright, Lubensky, \& Zhou, 
2013; Çakal, Hewstone, Schwär, \& Heath, 2011; Glasford \& Dovidio, 2011; Saguy, Tausch, Dovidio, \& Pratto, 2009; Sengupta \& Sibley, 2013; Tropp, Hawi, van Laar, \& Levin, 2012).

As Wright and Lubensky (2009) highlight, the prejudice reduction model of social change that underlies contact research contrasts with classic research on collective action. This indicates that the collective action taken by disadvantaged groups is promoted by factors that in fact disrupt positive intergroup relations (see van Zomeren, Postmes, \& Spears, 2008), such as strong ingroup identification (Stürmer \& Simon, 2004), negative outgroup emotions (Simon \& Klandermans, 2001), awareness of structural inequalities (van Zomeren, Spears, Fischer, \& Leach, 2004), and a heightened sense of injustice (Ellemers \& Barreto, 2009). Ironically, by promoting positive intergroup feelings and reducing identity salience, intergroup contact may sometimes undermine the collective action orientation of members of historically disadvantaged groups.

Saguy et al. (2009) provided initial evidence for this so-called "irony of harmony" effect of intergroup contact on social change, showing that contact inhibited social change by promoting disadvantaged group members' "unrealistic" expectations of equality. Positive contact may therefore encourage people to like one another more whilst reducing the motivation to challenge the status quo, a finding supported by a growing body of research (see McKeown \& Dixon, 2017, for a review). For instance, in a recent study examining the relations between disadvantaged (Blacks, Hispanics) and advantaged (Whites) groups in the US from the perspective of disadvantaged members, Hayward, Tropp, Hornsey, and Barlow (2018) found that positive contact was associated with reduced collective action intentions and behaviour via reduced anger toward the advantaged group and lower perceived discrimination.

On the other side, however, contact effects have also been found to foster social change motivations among disadvantaged group members. In two cross-sectional general population surveys, Kauff et al. (2016) showed that, in contexts where advantaged group members have more positive intergroup contact, disadvantaged group members are more rather than less likely to support their own rights. In the aforementioned study by Hayward et al. (2018), results also revealed direct positive associations between positive contact and collective action.

Although less numerous, some studies have also investigated the relationship between contact and social change tendencies among advantaged group members. Findings from these studies generally point to a positive association between contact and support for benefitting the relevant disadvantaged outgroup. For example, Reimer et al. (2017, Study 1b) found among heterosexual participants that positive contact was associated with greater collective action intentions supporting LGBT people, an effect mediated by identification with the LGBT movement. The positive association between positive contact and collective action was replicated in Study 2b, using a longitudinal approach. Selvanathan, Techakesari, Tropp, and Barlow (2017) showed in three studies that positive interracial contact was associated with stronger intentions of Whites to engage in collective action on behalf of Blacks, largely through its indirect effects on intergroup empathy and anger toward injustice. Further evidence shows that contact is sometimes positively associated with social change orientations and support for social policies favouring the disadvantaged group (Dixon, Durrheim, \& Tredoux, 2007; Vezzali \& Giovannini, 2011).

There are, however, also studies showing that contact effects are not particularly strong when it comes to advantaged group members' support for equality. For instance, friendships with South African Blacks related to Whites' sense that they cannot do much to change the situation of Blacks, which in turn related to weaker tendencies to act to promote equality (Çakal et al., 2011, Study 2). These findings echo much earlier work (Jackman \& Crane, 1986): among a nationally representative sample of White Americans, experiences of positive contact with Blacks predicted better racial attitudes, but less support for policies designed to redress racial inequalities in housing and employment (see also Dixon, Durrheim, \& Tredoux, 2005; Durrheim \& Dixon, 2004). 
Together, existing research on contact and social change can be summarized as indicating a negative association among the disadvantaged and, for the most part, a positive association among the advantaged (but with some mixed evidence). What is missing from current work is the question of mechanisms accounting for these different effects, and a simultaneous examination of an advantaged and a disadvantaged group. The current research addresses both of these gaps.

\section{Social Identity Theory, Intergroup Contact, and Social Change}

We situated our theoretical understanding of the relationship between contact and social change motivations within SIT (Tajfel \& Turner, 1979), a theory focused on understanding when and why individuals engage in collective actions aimed at changing the hierarchical structure of society. According to SIT, a relevant part of individuals' self-esteem derives from their social identity, which depends on the position of their ingroup in society. Being a member of an advantaged, high-status group should foster positive selfesteem, while being a member of a disadvantaged, low-status group should be related to lower self-esteem. According to Tajfel and Turner (1979), when social identity is devalued because the ingroup has low status, individuals may decide to adopt an individual (social mobility) or a collective (social change) strategy in order to improve self-esteem. The choice of the strategy largely depends on three sociostructural variables that influence individuals' perception of social hierarchies: the legitimacy and stability of status differences and the permeability of group boundaries.

Legitimacy of status differences indicates the extent to which disparities between groups are perceived as appropriate and fair; stability of status differences indicates the extent to which group position is seen as modifiable; permeability of group boundaries indicates whether or not one can freely move from the ingroup to the outgroup as an individual.

Research has demonstrated that members of subordinate groups are more likely to adopt a collective strategy when the relations with the higher status group are perceived as unstable and illegitimate and group boundaries are perceived as impermeable (Ellemers, 1993; Ellemers, Wilke, \& van Knippenberg, 1993; Mummendey, Klink, Mielke, Wenzel, \& Blanz, 1999; Tajfel, 1978; Turner \& Brown, 1978; van Zomeren, Leach, \& Spears, 2012). Considering the relation between East and West Germans from the perspective of East Germans, for example, Mummendey et al. (1999) found a positive relationship between the perception that intergroup relations were unstable, illegitimate, and impermeable, and increased social competition. Based on these considerations we predicted that, among disadvantaged group members, increased instability, illegitimacy, and impermeability of group boundaries will be associated with greater intentions to engage in actions for social change.

Existing research has focused mainly on the conditions that encourage disadvantaged group members to engage in collective action. Tajfel and Turner (1979) acknowledged that advantaged groups' perceptions that the existing status relations are illegitimate can threaten collective moral image, and lead advantaged group members to support actions for social change that can reduce the conflict of values as well as their shame and guilt over unfair ingroup advantages (e.g., Iyer, Leach, \& Crosby, 2003; Lickel, Schmader, \& Barquissau, 2004; Miron, Branscombe, \& Schmitt, 2006; Stewart, Latu, Branscombe, \& Denney, 2010; Swim \& Miller, 1999; see also Banfield \& Dovidio, 2013). Our prediction is therefore that, among advantaged group members, higher perceptions of status illegitimacy will be related to higher intentions to engage in actions for social change on behalf of the disadvantaged group.

Concerning status stability perceptions, research suggests that perceiving status relations as unstable may threaten advantaged group members' position in the status hierarchy (Scheepers \& Ellemers, 2005; Scheepers, Röell, \& Ellemers, 2015), which may in turn motivate them to preserve their own advantage via increased ingroup bias. Given that greater levels of ingroup bias can be equated to lower levels of motivation to engage in actions on behalf of 
disadvantaged groups, we predicted that greater instability will be associated with lower social change motivation amongst the advantaged.

We further predicted that among advantaged group members there would be a negative association between permeability and social change motivation for two reasons. First, perceiving group boundaries as highly permeable may threaten the distinctiveness and superiority of the advantaged group in some contexts (Jetten, Spears, \& Postmes, 2004), increasing their resistance to social change. Second, permeability may feed into the individualistic ideology of meritocratic advancement, which is at the heart of the "American Dream." If boundaries between classes are seen as permeable, why do we need collective action to redress class inequality, either on the part of the historically advantaged or on the part of the historically disadvantaged?

Research investigating the relation between contact and the three sociostructural variables associated with SIT is limited, especially research that considers the behaviours of both advantaged and disadvantaged group members. A partial exception is provided by Tausch, Saguy, and Bryson (2015), who examined the relation between Whites and Latino Americans in the US from the perspective of ethnic minority group members. The authors found that the negative relation between cross-group friendships and collective action orientation was mediated by decreased identification with the disadvantaged group, but not by changes in perceived permeability of group boundaries. Instead, higher permeability mediated the relationship between cross-group friendships and individual mobility orientation. Unfortunately, the authors only focused on the disadvantaged group, and did not consider perceived legitimacy and status stability in their model. The present study aims to address this gap.

Broadly, our hypothesis is that contact influences perceptions of the three sociostructural variables, which in turn mediate contact effects on intentions to engage in collective action.

With respect to disadvantaged groups, research shows that intergroup contact can lead members to expect a fairer treatment by the advantaged group and to pay less attention to intergroup inequalities (Saguy et al., 2009). Therefore, we expect positive contact to be associated with increased perceptions of disadvantaged group members that the system is legitimate and stable. Moreover, if contact deflects attention away from inequalities, it may also foster perceptions of permeability. Thus, for disadvantaged group members, contact may be associated with reduced motivation for social change via an increase in perceptions of the social system as legitimate and stable, and of group boundaries as permeable.

With respect to advantaged groups, in line with the idea that it fosters social harmony by reducing the conditions that lead to intergroup conflict (see Wright \& Lubensky, 2009), contact can predict lower social change motivation by increasing perceptions that the system is stable and that group boundaries are permeable. Predictions are less straightforward for legitimacy perceptions. On the one hand, contact may reduce attention to inequalities, therefore increasing perceptions of legitimacy (and in turn lowering social change motivation). On the other hand, contact might also lead advantaged group members to recognize that status relations are characterized by social inequalities and therefore are illegitimate, in turn leading to greater social change motivation (Iyer et al., 2003). Note that this latter possibility would be in line with the finding that contact is generally associated with greater intentions for social change among the advantaged group (Saguy et al., 2017). Both possible directions between contact and legitimacy perceptions were explored in the current work.

Our predictions regarding the effects of contact on the social change motivations of historically advantaged group members involve seemingly contradictory paths. In fact, we predict that contact will lead to lower social change motivation via increased status stability and permeability, but to higher social change motivation via reduced legitimacy. We would argue, however, that this inconsistency is only apparent. In fact, as we have argued, research on advantaged group members has produced somewhat mixed findings, even if more studies have shown that contact is associated with 
greater willingness to engage in social change on behalf of the disadvantaged group than vice versa. The examination of underlying processes, which is a strong aspect of this study, may shed light on this relationship. In particular, it is possible that contact has differential effects produced by different processes, potentially leading both to perceptions of system stability, therefore inhibiting social change, and to perceptions of injustice, therefore motivating collective action.

\section{The Moderating Role of Membership Salience and Content of Contact}

There is reason to believe that both membership salience and content of contact might moderate the effects of contact on collective action. Various authors have noted that salience of social identity is key to fostering collective action (e.g., van Zomeren et al., 2008; Wright \& Lubensky, 2009). Generally, membership salience has been operationalized in the contact literature (and in this research) as the interactants' awareness during contact of belonging to different groups (see e.g., Greenland \& Brown, 1999; Harwood, Hewstone, Paolini, \& Voci, 2005; Voci \& Hewstone, 2003). Contact research has repeatedly found that membership salience moderates contact effects, such that contact effects are stronger and more generalizable when membership salience is high (Brown \& Hewstone, 2005). Indirect evidence for the moderating role of membership salience when collective action is concerned is provided by work showing that dual identity (where membership salience is preserved within a common identity representation) is associated with greater motivation for social change and willingness to protest against blatant discrimination among both advantaged and disadvantaged group members (Banfield \& Dovidio, 2013, Study 3; Glasford \& Calcagno, 2012; Glasford \& Dovidio, 2011).

Similarly, positive contact focused on commonalities between groups might obscure group differences and undermine the motivation to act for a more equal society (Saguy \& Chernyak-Hai, 2012; Saguy et al., 2009). Conversely, focusing the attention on group differences, in terms of inequality of the status relationship, may foster collective action intentions. As an example, some studies showed that supportive contact, defined as contact where advantaged group members acknowledge status inequality by communicating respect to the disadvantaged group, is associated with stronger intentions to engage in collective action among disadvantaged group members (Becker et al., 2013; Droogendyk, Louis, \& Wright, 2016; Glasford \& Johnston, 2018). More direct evidence, in this case for advantaged group members, was provided by Vezzali et al. (2017), who conducted a correlational study among Italian university students. They found that the number of friendships with immigrants was associated with greater social change motivation only when differences (vs. commonalities) between groups were salient during contact. This study, however, did not include the perspective of disadvantaged group members and did not examine potential mediators of the effects found.

\section{The Current Research}

Our primary aim was to test whether sociostructural variables identified by SIT (status legitimacy and stability, and permeability of group boundaries) mediate the relationship between contact and social change motivation among both advantaged and disadvantaged group members. In addition, we tested membership salience and content of contact (difference-focused vs. commonality-focused) as potential moderators of these relationships, with exploratory purposes.

Participants were Italian and immigrant high school students in Emilia-Romagna, a region that at the time of data collection was characterized by a high percentage of immigrants $(11.2 \%)$ compared to the general Italian context (7.3\%), a difference that has constantly increased over the last 10 years. In this context, immigrants qualify as the disadvantaged group, as shown, for instance, by an indicator of risk of poverty that reached $22.7 \%$ in families composed by immigrants, compared to $2.9 \%$ for Italian families (Italian National Institute of Statistics, 2015). Relationships between Italians and immigrants 
are conflictual (Pew Research Center, 2007), as also demonstrated by research conducted in educational contexts (Di Bernardo, Vezzali, Stathi, Cadamuro, \& Cortesi, 2017; Vezzali, Stathi, \& Giovannini, 2012). However, although attitudes toward immigrants are quite negative, they have remained relatively stable in the last years (European Commission, 2018a, 2018b); according to data derived from the Eurobarometer in $2014,42 \%$ of respondents indicated having fairly negative feelings toward non-EU immigrants; in 2018, the corresponding percentage was $40 \%$. Regarding immigrants attending high schools, the difference between Emilia-Romagna (where data collection took place) and Italy is generally large $(15.3 \%$ vs. $7.0 \%$; Regione Emilia-Romagna, 2017). Therefore, we believe the examination of this context is topical and can contribute significantly to understanding social change processes. We also highlight that our sample was comprised of adolescent participants, a target group that has generally been underinvestigated in contact research related to social change; this way, we aim to provide evidence on how to mobilize young people toward the attainment of racial equality.

To outline, based on the literature reviewed in the previous lines, our hypotheses are the following:

H1a: Among the advantaged group, contact should be associated with lower intentions to engage in social change, via heightened perceptions of status stability and permeability of group boundaries.

H1b: Among advantaged group members, the potential effects of perceived status stability and permeability of group boundaries should be offset by lower perceptions of status legitimacy, which will in turn predict higher social change motivation.

H2: Among the disadvantaged group, contact should be associated with higher status stability, legitimacy, and permeability of group boundaries, which in turn should mediate contact effects on lower motivation for social change.
We also explored membership salience and content of contact as potential moderators. The two concepts, although linked, are conceptually distinct. Membership salience per se does not necessarily entail discussion of commonalities, differences, or inequalities, which are instead captured by measures of commonality-focused and differencefocused contact (see e.g., Saguy et al., 2009; Vezzali et al., 2017). However, given the exploratory nature of this test, we do not make specific hypotheses.

Although we consider both quantity and quality of contact, we do not make specific predictions about their differential effects. However, we acknowledge that, since quality of contact is especially relevant to attitude change (Hodson \& Hewstone, 2013), effects may be stronger for quality than for quantity of contact.

\section{Method}

\section{Participants and Procedure}

First, we discussed the study and its aims with representatives of the city municipality involved directly in the educational domain. Second, we contacted the school governors to obtain their initial approval for the research (provided by the school councils of the schools involved), after disclosing full procedures and material. Third, we provided informed consent forms to parents (in the case of participants who were underage) and to students, clarifying the aims and procedures of the study, assuring that participation was voluntary and that they could withdraw from the study at any time without consequence. Participants included in the final sample (two students refused participation) were 557 high school students (256 male, 295 female, six data missing; age ranged from 14 to 21 years, $\left.M_{\text {age }}=17.08, S D=1.36\right)$ from different high schools situated in Emilia-Romagna, a Northern Italian region. The Italian sample consisted of 392 participants (194 male, 194 female, four data missing; $M_{\text {age }}=16.94, S D=1.34$ ), while the immigrant sample included 165 respondents (62 male, 101 female, two data missing; $\left.M_{\text {age }}=17.41, S D=1.36\right)$. The distinction between Italian and immigrant participants was made on 
the basis of the information provided by the schools, taking into account the students' family background (i.e., whether participants had immigrant parents). Immigrants were predominantly from Africa (40.6\%), followed by Eastern Europe (32.7\%), Asia (23\%), and South America (3\%); one missing $(0.6 \%)$. Questionnaires were administered to the students during class time.

Since the number of participants depended on school's availability (e.g., number of classes provided, students' absences in the day of data collection), we calculated 246 participants as an a priori minimum sample size allowing a power of 0.8 to detect a medium to small effect size, employing structural equation models with six latent variables and 12 observed variables (Cohen, 1988), and with the goal of conducting a mediation analysis, where we would be testing indirect effects employing bias-corrected bootstrapped estimates (Fritz \& MacKinnon, 2007). Since the aimed sample size was not reached for the immigrant sample, a post hoc power analysis revealed that 165 respondents allowed a power of 0.8 , with a medium to small effect size for testing the hypothesized model employing structural equation with observed variables.

\section{Measures}

Italian students completed measures involving contact with immigrants, whereas immigrants completed measures involving contact with Italians. The full list of items used is presented in the online supplemental material. Unless otherwise specified, all items had a 5 -point scale $(1=$ not at all, $5=$ very much).

Quantity of contact. Quantity of contact was assessed using five items. Participants were asked to indicate the extent to which they had contact with immigrants/Italians at school, in the neighbourhood, during free time, and in general, and how many immigrants/Italians they spent time with. For the first four items, responses ranged from 1 (none) to 5 (very much); for the latter item, possible responses were: 1 (none), 2 (one or two), 3 (three or four), 4 (five or six), 5 (more than six; $\alpha=.88$ ).
Quality of contact. Participants were asked to evaluate their interactions with immigrants/Italians using four bipolar words (e.g., competitive/cooperative, rude/kind) adapted from previous studies (e.g., Capozza, Trifiletti, Vezzali, \& Favara, 2013). On a 5 -point scale, 1 was assigned to the negative pole, 5 to the positive pole, 3 was the neutral point (neither, nor, $\alpha=.83$ ).

Status stability. A two-item scale $(r=.21, p<.001)$, adapted from Mummendey et al. (1999), was employed to measure the perception of stability of the status relationship (e.g., "Do you think that the living conditions of Italians and immigrants will be the same in the next years?").

Status legitimacy. The perception of legitimacy of status differences was measured with three items (e.g., "Are differences in society between Italians and immigrants legitimate?") adapted from Saguy, Dovidio, and Pratto (2008; see also Vorauer \& Sakamoto, 2008; $\alpha=$.78).

Permeability of group boundaries. Participants rated their perceptions of permeability using two items (reverse-coded) adapted from Major et al. (2002; e.g., "How easy is that immigrant individuals improve their status in Italian society?"). Correlation between items was .48, $p<.001$.

Social change motivation. Participants were asked to respond to four items that measured their willingness to engage in collective action on behalf of immigrants (e.g., "Do you think you should take part in actions toward equality between Italians and immigrants?") adapted from Saguy et al. (2008) and from Glasford and Dovidio (2011; $\alpha=.85)$.

Membership salience. Two items $(r=.28, p<.001)$, taken from Vezzali and Capozza (2011), assessed membership salience during contact with the outgroup (e.g., "When you have contact with immigrants [Italians], on average, do you think about the fact that you belong to different cultures?").

Content of contact. In order to assess commonalityfocused and difference-focused contact, six items 
Table 1. Means and standard deviations of the constructs.

\begin{tabular}{lcccc}
\hline Measures & $\begin{array}{c}\text { Italians } \\
(N=392)\end{array}$ & $\begin{array}{c}\text { Immigrants } \\
(N=165)\end{array}$ & $t(555)$ & Cohen's $d$ \\
\hline Quantity of contact & $2.78(1.01)$ & $3.84(1.03)$ & $11.25^{* * *}$ & 1.04 \\
Quality of contact & $3.61(0.86)$ & $3.94(0.70)$ & $4.69^{* * *}$ & 0.39 \\
Stability & $2.73(0.73)$ & $2.94(0.63)$ & $3.41^{* * *}$ & 0.31 \\
Permeability & $2.88(0.98)$ & $3.11(1.00)$ & $2.56^{*}$ & 0.23 \\
Legitimacy & $2.43(1.03)$ & $1.99(0.82)$ & $5.28^{* * *}$ & 0.47 \\
Social change motivation & $2.91(1.03)$ & $3.79(0.78)$ & $11.13^{* * *}$ & 0.96 \\
Membership salience & $2.78(0.97)$ & $2.99(0.99)$ & $2.31^{*}$ & 0.20 \\
Content of contact & $-0.50(1.16)$ & $-0.61(1.13)$ & 1.03 & 0.10 \\
\hline
\end{tabular}

Note. All measures had a 5-point scale. Content of contact $=$ difference between difference-focused contact scores and commonality-focused contact scores: higher scores reflect more difference-focused than commonality-focused contact. ${ }^{*} p<.05 .{ }^{* * *} p<.001$.

were adapted from Saguy and Dovidio (2013) and Saguy et al. (2009); three items $(\alpha=.76)$ assessed commonalities (e.g., "In general, when you have contact with immigrants, do you speak about things that Italians and immigrants have in common?") and three items $(\alpha=.72)$ measured differences (e.g., "In general, when you have contact with immigrants, do you discuss about cultural differences between Italians and immigrants?") during contact.

\section{Results}

For each variable, a composite score was created by averaging the relative items. For the content of contact measure, along with the two separate means, an index of content of contact was created by calculating the difference between differences and commonalities scores: the higher the score, the greater the focus on differences rather than similarities. Descriptive statistics are reported in Table 1. Correlations for the Italian and the immigrant sample are provided in Table 2.

\section{Main Analyses}

To test the hypothesized relationships, we used a multigroup structural equation model.

Italian sample (advantaged group). A multigroup structural equation model with latent variables was applied. For each latent construct, two parcels were created, corresponding to the two original items for measures composed by two items, or using the item-to-construct balance method (Little, Cunningham, Shahar, \& Widaman, 2002) for measures where more than three items were used (i.e., the items were separated in order to create two parcels with similar loadings). Employing item aggregation instead of keeping items separated is generally convenient (e.g., higher reliability and commonality, increased model stability) and, since parcelling decreases the number of parameters to be estimated (thus reducing the number of participants required), it is useful for small sample sizes (for a comprehensive explanation of the advantages and disadvantages of parcels, see Little et al., 2002; see also Hau \& Marsh, 2004). We allowed correlations between the three mediators.

The model presented a good fit to data, $\chi^{2}(41)$ $=62.67, p<.05 ; \chi^{2} / d f=1.53 ; \mathrm{CFI}=0.99$; $\mathrm{SRMR}=.03$. As can be seen in Figure 1, supporting $\mathrm{H} 1 \mathrm{~b}$, both quality and quantity of contact were associated with lower perceived legitimacy; in turn, higher levels of perceived legitimacy were negatively associated with support for social change. Regarding the other two potential mediators, results showed, in line with the literature (Wright \& Lubensky, 2009), a positive association between contact (quality and quantity) and both perceived stability and permeability of group 
Table 2. Zero-order correlations between constructs for Italian and immigrant samples.

\begin{tabular}{|c|c|c|c|c|c|c|c|c|}
\hline & 1 & 2 & 3 & 4 & 5 & 6 & 7 & 8 \\
\hline \multicolumn{9}{|l|}{ Italian sample $(N=392)$} \\
\hline 1. Quantity of contact & - & & & & & & & \\
\hline 2. Quality of contact & $.51 * * *$ & - & & & & & & \\
\hline 3. Membership salience & -.10 & $-.21 * * *$ & - & & & & & \\
\hline 4. Content of contact & $-.37 * * *$ & $-.40 * * *$ & $.32^{* * *}$ & - & & & & \\
\hline 5. Stability & .04 & $.10^{*}$ & $-.13 * *$ & $.20 * * *$ & - & & & \\
\hline 6. Legitimacy & $-.30 * * *$ & $-.35^{* * *}$ & $.35^{* * *}$ & $-.33 * * *$ & -.08 & - & & \\
\hline 7. Permeability & $.25^{* * *}$ & $.21 * * *$ & $-.11 *$ & $.20 * * *$ & .01 & -.07 & - & \\
\hline 8. Motivation for social change & $.43^{* *}$ & $.45^{* * *}$ & $-.23 * * *$ & $.39 * * *$ & $.17 * * *$ & $-.58 * * *$ & $.19 * * *$ & - \\
\hline \multicolumn{9}{|l|}{ Immigrant sample $(N=165)$} \\
\hline 1. Quantity of contact & - & & & & & & & \\
\hline 2. Quality of contact & $.45^{* * *}$ & - & & & & & & \\
\hline 3. Membership salience & -.02 & -.03 & - & & & & & \\
\hline 4. Content of contact & $-.25^{* * *}$ & $-.22 * *$ & $.22 * * *$ & - & & & & \\
\hline 5. Stability & .04 & .11 & .09 & .09 & - & & & \\
\hline 6. Legitimacy & $-.26 * * *$ & $-.23^{* *}$ & .00 & $-.18^{*}$ & -.03 & - & & \\
\hline 7. Permeability & $.16^{*}$ & $.17 *$ & .11 & .09 & $.19 *$ & .10 & - & \\
\hline 8. Motivation for social change & $.23^{* *}$ & $.20^{*}$ & $.27 * * *$ & -.05 & .14 & $-.17^{*}$ & $.20^{* *}$ & - \\
\hline
\end{tabular}

Note. Content of contact $=$ higher scores reflect more difference-focused than commonality-focused contact. ${ }^{*} p<.05 .{ }^{* *} p<.01 .{ }^{* * *} p<.001$.

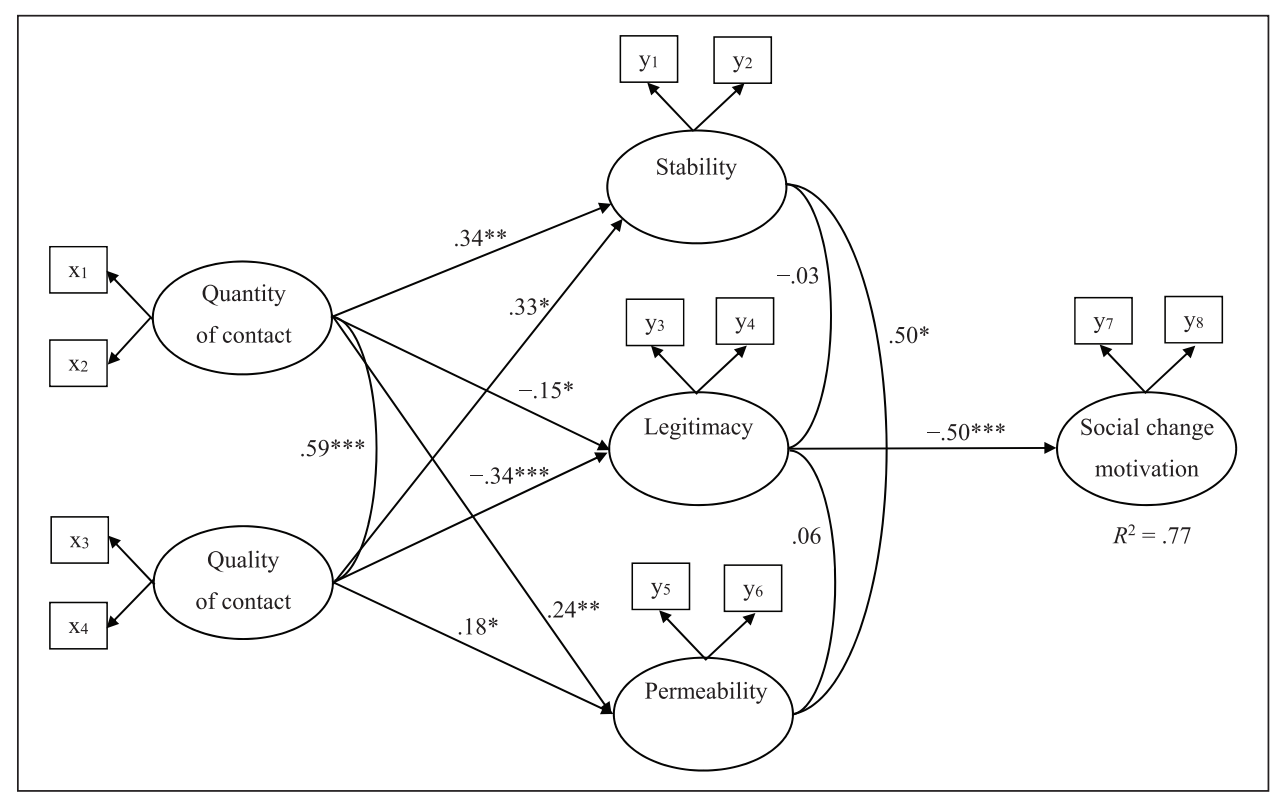

Figure 1. Path analysis with latent variables, Italian sample $(N=392)$.

Note. Standardized regression coefficients are presented. Only significant paths are included. ${ }^{*} p<.05 .{ }^{* *} p<.01 .{ }^{* * *} p<.001$. 
boundaries. However, no relations emerged between these two mediators and respondents' social change motivations. Therefore, $\mathrm{H} 1 \mathrm{a}$ and $\mathrm{H} 1 \mathrm{~b}$ received mixed support as regards status stability and permeability perceptions.

To test the effect of quality and quantity of contact on social change motivation through the indirect effect of perceived legitimacy, a bootstrap method with 5,000 resamples was applied. For quality of contact, the point of estimate was .22 and the $95 \%$ confidence interval fell 0.07 and 2.72 . For quantity of contact, the point of estimate was .12 with a confidence interval of between 0.01 and 0.49 . Since neither interval included zero, the indirect effect on greater social change motivation via reduced perceived legitimacy was significant for both quality and quantity of contact. Therefore, our findings supported $\mathrm{H} 1 \mathrm{~b}$, according to which a meaningful mediator for the association between contact and increased social change motivation is legitimacy perceptions.

Immigrant sample (disadvantaged group). The model presented before was also tested for the immigrant sample. However, since the sample size was too small to perform the multigroup analysis with latent variables (see Participants section), we applied structural equation modelling with observed variables. The model showed an adequate fit to data, $\chi^{2}(2)=3.94, p=.14$; $\chi^{2} / d f=1.97$; CFI $=0.98$; SRMR $=.03$. As can be seen in Figure 2, a negative relation between quantity of contact and perceived legitimacy emerged. In addition, legitimacy was negatively associated with motivation for social change. Surprisingly, positive associations between perceived stability and permeability with motivation for social change also emerged. These relationships do not support $\mathrm{H} 2$.

The significance of the mediation path from quantity of contact to motivation for social change via decreased perceived legitimacy was evaluated with a bootstrapping procedure that used 5,000 resamples. As the 95\% confidence interval did not include zero ([0.003, 0.12]; point of estimate $=.03$ ), the indirect effect was significant.

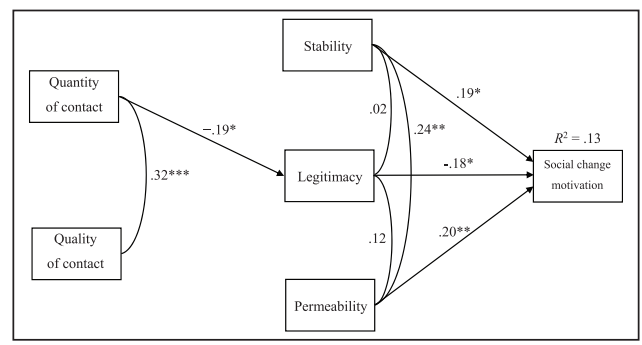

Figure 2. Path analysis with observed variables, immigrant sample $(N=165)$.

Note. Standardized regression coefficients are presented. Only significant paths are included.

${ }^{*} p<.05 . * * p<.01 .{ }^{* * *} p<.001$.

\section{Secondary Analyses}

Italian sample. The moderation effect of membership salience and of content of contact was investigated by applying the multiple group analysis simultaneously for high and low levels of membership salience, as determined by a median split. This way of testing moderation is generally considered reliable (see e.g., Iacobucci, Posavac, Kardes, Schneider, \& Popovich, 2015) and is commonly used in psychological research when applying structural equation modelling (see e.g., Her, Shin, \& Pae, 2018; Vezzali, Cadamuro, Versari, Giovannini, \& Trifiletti, 2015; Voci \& Hewstone, 2003).

For membership salience, the model in which coefficients were not constrained showed an excellent fit to data, $\chi^{2}(82)=85.31, p=.38$; $\chi^{2} / d f=1.04 ; \mathrm{CFI}=1.00 ; \mathrm{SRMR}=.04$. In order to test the invariance of the measurement model, and to obtain a baseline model, we constrained the factor loadings. From the chi-square difference test, it emerged that the two models were equivalent, $\chi^{2}(88)=89.62, \Delta \chi^{2}(6)=4.31$, $n s$. In the second step, when all parameters were constrained, a significant difference between the two models was found, $\chi^{2}(119)=149.17$, $\Delta \chi^{2}(31)=59.55, p<.001$. From the analysis of the single paths, we found a moderating effect of membership salience on the relationship between quality of contact and perceived legitimacy, $\chi^{2}(89)=96.70, \Delta \chi^{2}(1)=7.08, p<.01$. Quality of contact was associated with reduced 
Table 3. Model comparisons for the Italian and immigrant samples.

\begin{tabular}{|c|c|c|c|c|c|c|c|c|}
\hline Type & Model & $d f$ & $\chi^{2}$ & $\chi^{2} / d f$ & CFI & SRMR & AIC & CAIC \\
\hline \multicolumn{9}{|c|}{ Italian sample $(N=392)$} \\
\hline Main & Contact $\rightarrow \mathrm{SSF} \rightarrow \mathrm{SCM}$ & 41 & $62.67^{*}$ & 1.53 & 0.99 & .03 & 135.23 & 319.17 \\
\hline Main multi & Contact $\rightarrow$ SSF $\rightarrow$ SCM (low salience) & 41 & 33.15 & 0.81 & 1.00 & .03 & 105.98 & 263.31 \\
\hline Main multi & Contact $\rightarrow$ SSF $\rightarrow$ SCM (high salience) & 41 & 52.16 & 1.27 & 0.99 & .04 & 125.03 & 284.25 \\
\hline Main multi & Contact $\rightarrow$ SSF $\rightarrow$ SCM (low diff.) & 41 & 57.75 & 1.41 & 0.99 & .04 & 130.45 & 288.17 \\
\hline Main multi & Contact $\rightarrow$ SSF $\rightarrow$ SCM (high diff.) & 41 & 53.63 & 1.31 & 0.99 & .04 & 125.56 & 283.28 \\
\hline Alternative & Contact $\rightarrow \mathrm{SSF} \rightarrow$ Salience $\rightarrow$ SCM & 60 & 73.28 & 1.22 & 1.00 & .03 & 162.06 & 385.77 \\
\hline Alternative & Contact $\rightarrow$ SSF $\rightarrow$ Content $\rightarrow$ SCM & 49 & 61.28 & 1.25 & 1.00 & .03 & 143.45 & 352.24 \\
\hline Alternative & $\mathrm{SSF} \rightarrow \mathrm{SCM} \rightarrow$ Salience $\rightarrow$ Contact & 64 & $107.26^{* * *}$ & 1.68 & 0.98 & .04 & 193.09 & 396.91 \\
\hline Alternative & $\mathrm{SSF} \rightarrow \mathrm{SCM} \rightarrow$ Content $\rightarrow$ Contact & 53 & $139.74 * * *$ & 2.64 & 0.98 & .10 & 204.27 & 393.18 \\
\hline \multicolumn{9}{|c|}{ Immigrant sample $(N=195)$} \\
\hline Main & Contact $\rightarrow \mathrm{SSF} \rightarrow \mathrm{SCM}$ & 2 & 3.94 & 1.97 & 0.98 & .03 & 41.90 & 119.91 \\
\hline Main multi & Contact $\rightarrow$ SSF $\rightarrow$ SCM (low salience) & 2 & 8.92 & 4.46 & 0.93 & .05 & 46.51 & 114.24 \\
\hline Main multi & Contact $\rightarrow$ SSF $\rightarrow$ SCM (high salience) & 2 & 2.62 & 1.31 & 0.97 & .03 & 40.57 & 10.02 \\
\hline Main multi & Contact $\rightarrow$ SSF $\rightarrow$ SCM (low diff.) & 2 & 5.95 & 2.97 & 0.94 & .05 & 43.74 & 109.15 \\
\hline Main multi & Contact $\rightarrow$ SSF $\rightarrow$ SCM (high diff.) & 2 & 0.08 & 0.04 & 1.00 & .01 & 38.08 & 102.34 \\
\hline Alternative & Contact $\rightarrow$ SSF $\rightarrow$ Salience $\rightarrow$ SCM & 4 & 6.41 & 1.60 & 0.98 & .03 & 54.30 & 152.84 \\
\hline Alternative & Contact $\rightarrow$ SSF $\rightarrow$ Content $\rightarrow$ SCM & 4 & $14.56^{* *}$ & 3.64 & 0.92 & .06 & 61.94 & 160.48 \\
\hline Alternative & $\mathrm{SSF} \rightarrow \mathrm{SCM} \rightarrow$ Salience $\rightarrow$ Contact & 8 & $33.14^{* * *}$ & 4.14 & 0.82 & .11 & 70.26 & 152.37 \\
\hline Alternative & $\mathrm{SSF} \rightarrow \mathrm{SCM} \rightarrow$ Content $\rightarrow$ Contact & 8 & $45.86^{* * *}$ & 5.73 & 0.73 & .11 & 81.40 & 163.51 \\
\hline
\end{tabular}

Note. "Contact" includes both quality and quantity (tested separately as in the main models); SSF = sociostructural factors (i.e., legitimacy, stability, and permeability); SCM = social change motivation; diff. = index of content of contact (the higher the score, the greater the focus on differences rather than similarities). Main = main model; Main multi $=$ main model multigroup. ${ }^{*} p<.05 .{ }^{* *} p<.01 .{ }^{* * *} p<.001$.

perceived legitimacy when membership salience was high $(\beta=-.48, p<.001)$, but not when it was low $(\beta=-.08, n s)$. The indirect effect of perceived legitimacy with high membership salience was significant (point of estimate $=.63$, 95\% CI $[0.07,4.31])$.

For content of contact, the analysis did not converge, thus the moderator effect could not be interpreted since the data did not fit the model. Thus, for the Italian sample, performing a moderation analysis using content of contact as the moderating variable was not possible.

Immigrant sample. Similarly, in the case of the immigrant sample, a multiple group analysis with observed variables was conducted. Concerning membership salience, in the first step, coefficients were allowed to be freely estimated. This model showed a reasonable fit to data, $\chi^{2}(4)=11.54$, $p<.05 ; \chi^{2} / d f=2.89 ; \mathrm{CFI}=0.94 ; \mathrm{SRMR}=.03$. Then, we constrained all other coefficients in order to test whether differences emerged with the baseline model. Findings showed that group salience did not moderate the relation between contact and motivation for social change, $\chi^{2}(23)$ $=35.52, \Delta \chi^{2}(19)=23.98, n s$.

Regarding the content of contact index, the model where the coefficients were estimated without any constraint presented excellent fit indexes, $\chi^{2}(4)=5.26, p=.26 ; \chi^{2} / d f=1.31$; CFI $=0.99 ;$ SRMR $=.01$. When constraining all coefficients, the chi-square difference test was significant, $\chi^{2}(23)=51.86, \Delta \chi^{2}(19)=46.60$, $p<.001$. When each path was individually constrained, a moderating effect on the relationship between contact quality and perceived status stability was observed, $\chi^{2}(5)=10.49, \Delta \chi^{2}(1)=$ 5.23, $p<.05$ : the association between contact 
quality and perceived stability was significant when the interaction was focused more on differences rather than on similarities $(\beta=.36$, $p<.01$ ), while the coefficient turned out to be nonsignificant for low levels of the moderator $(\beta=-.03, n s)$. No other relevant differences emerged. However, when bootstrapping was applied, testing the significance of the indirect effect of contact quality on social change motivation via perceived stability for high levels of the moderator, the $95 \% \mathrm{CI}$ did include zero ( $[-0.04$, 0.20 , point of estimate $=0.05)$, thus the mediation was nonsignificant. ${ }^{1}$

\section{Discussion}

The current research attempted to integrate contact research on collective action with research on SIT, by testing sociostructural variables as mediators between contact and social change motivation. It did so by considering a sample of both advantaged (Italians) and disadvantaged (immigrants) group members. As both theories speak to the problem of intergroup inequality, it is surprising that research on intergroup contact has generally neglected the contribution of SIT in explaining collective action (for exceptions, see e.g., Çakal, Hewstone, Güler, \& Heath, 2016; Tausch et al., 2015), even if SIT has informed a substantive body of work on how intergroup contact can reduce intergroup prejudice and stereotyping (see Brown \& Hewstone, 2005; Hodson \& Hewstone, 2013). As a secondary and exploratory aim, we investigated membership salience and content of contact (focus on differences vs. commonalities) as moderators, to test whether contact effects were stronger when salience of group identity, or a greater focus on differences than on commonalities, were high.

Among advantaged group members, both frequency and quality of contact were associated with the three sociostructural variables: positively with perceived status stability and permeability, and negatively with perceived legitimacy. In line with the notion that contact may sometimes inhibit social change, contact was associated with increased perceptions of permeability and stability. Both variables were expected to inhibit social change, however, we did not find support for this prediction.

Support for our hypotheses was especially provided by perceptions of legitimacy: quantity and quality of contact were associated with reduced perceptions that the system is legitimate; in turn, greater illegitimacy perceptions were associated with stronger intentions to engage in actions for social change. Note that we had also acknowledged the possibility that contact would be associated with greater perceived legitimacy, in line with research arguing for a sedative effect of contact, but in contrast with the majority of research showing that, among advantaged group members, contact is associated with greater support for social change on behalf of disadvantaged groups (Dixon, Durrheim, \& Thomae, 2017). In fact, supporting the beneficial effect of contact on social change motivation for the advantaged, this does not appear to be the case: the fact that contact is associated with stronger awareness of stability of the system does not seem to be in contrast with awareness of societal injustices, which in this study was found to be the determinant of one's intentions to act to support intergroup equality.

Surprisingly, we did not find associations of perceived stability and permeability with social change motivation within our structural model. Note that both perceived stability and permeability were associated with social change motivation (see Table 2). Possibly, in this context, legitimacy perceptions were considered as more relevant to the choice to engage in action to support the disadvantaged group such that, when the three variables were entered as simultaneous predictors of social change motivation, only the effects of perceived legitimacy emerged as significant.

Also, note that these correlations were in the opposite direction than expected, namely perceived stability and permeability were both positively related to social change motivation. Possibly, the more that advantaged group members perceived the hierarchical situation as stable, the more they recognized the need to engage in actions to change the status quo. Also, the more 
the group boundaries were perceived as permeable, but within a broader context in which immigrants clearly represented the disadvantaged group, the more advantaged group members were motivated to reinforce actions that would ultimately lead to social equality.

Consistent with SIT predictions (e.g., Ellemers, 1993), results concerning the disadvantaged group revealed that perceived illegitimacy was associated with greater social change motivation. The positive association between perceived stability and social change motivation, although unpredicted, is not totally surprising. Scheepers et al. (Scheepers, Spears, Doosje, \& Manstead, 2006), for instance, demonstrated that extreme actions to change the status hierarchy can be enacted by the disadvantaged group as an ultimate measure. In other words, when the status hierarchy is perceived as stable, low-status group members may believe that only extreme acts can change it. In the case of our study, possibly, disadvantaged members perceived social change actions as the extreme but still appropriate way to face their unfair position. An important point for future research would be to include measures of normative and nonnormative collective action intentions (Becker \& Tausch, 2015), and test when perceived status (in)stability stemming from contact is associated with collective action intentions, and specifically with what type of collective action (normative or nonnormative).

Unexpectedly, among disadvantaged group members, perceived permeability was positively associated with social change motivation. Possibly, in this particular context, the more participants perceived that their group can advance in society at the individual level (given the permeable intergroup boundaries), the more they perceived the situation as granting rights to them despite their low status (since they can advance, individually, in society), thus leaving space for obtaining even more rights and motivating them to engage in actions for social change.

Notably, among disadvantaged group members, quantity of contact was indirectly associated with greater social change motivation via reduced perceived legitimacy. The first explanation for this finding parallels the one provided for advantaged members, namely that repeated interactions demonstrate that the unequal position in the status hierarchy is not fair (an effect even reinforced by the fact that disadvantaged members display a higher contact quantity; see Table 1). Future research can explore the role of fairness as an alternative underlying factor of the aforementioned relationship. Results are also in line with research showing that, in some cases, contact can increase awareness of group discrimination (Poore et al., 2002). In the case of our study, (quantity of) contact may have increased perceptions of unequal intergroup relations, therefore making salient group distinctions and fostering perceptions of status illegitimacy. The fact that contact quality was not significantly related to social change motivation is in line with studies showing that contact is less effective among disadvantaged group members (Tropp \& Pettigrew, 2005) and, more specifically, that this differential effect especially applies to quality of contact (Vezzali, Giovannini, \& Capozza, 2010). Note, however, that this finding is specific to research on prejudice, and additional research is needed to understand the direction of moderation by group for quantity and quality of contact, when the outcome is represented by measures relating to collective action.

It is worth noting that, both for advantaged and disadvantaged group members, perceived legitimacy of status differences emerged as the key mediator of the association between contact and greater social change motivation. These results are in line with findings showing that perceived legitimacy is an especially relevant factor in determining the likelihood that individuals will engage in actions aimed at social change (e.g., Becker et al., 2013; Sweetman, Spears, Livingstone, \& Manstead, 2013; van Zomeren et al., 2012; Wellman, Liu, \& Wilkins, 2016). We argue that results regarding advantaged group members, considering the high percentage of variance explained (77\%), are especially interesting in that they show that, consistent with SIT predictions, when superior status is perceived as illegitimate (as a function of heightened intergroup contact), 
advantaged group members may act against their ingroup, either by leaving it or (as in the case of the present study) by supporting actions for redressing inequality (see also Hays \& Blader, 2017; Saguy \& Dovidio, 2013; Saguy et al., 2008).

Results concerning moderation by membership salience and content of contact were less clear. Among advantaged group members, we found that the indirect effect of quality of contact on social change motivation was only significant when membership salience was high. This result is in line with the role that membership salience has in the generalization of contact effects (Brown \& Hewstone, 2005), and reveals that positive contact has an empowerment function on collective action primarily when individuals are aware of group distinctions during contact. Our interpretation is that positive interactions with outgroup members, when group salience is high and therefore individuals are more likely to address group differences (see Table 2), cultivate the idea that the subordinate position of immigrants in Italy is unfair, which in turn promotes the intention to act for social change (Tajfel \& Turner, 1979). In addition, quality of contact with high membership salience may have increased participants' sensitivity to inequalities by enhancing perception of guilt (see Swim \& Miller, 1999). By contrast, effects of quantity of contact were unmoderated, both for the advantaged and the disadvantaged group, revealing a limited role of membership salience in the context of repeated interactions, irrespective of group valence. Tests of moderation for content of contact were not relevant to mediation effects for either group.

Note that the present results do not support the sedative effect of contact (Çakal et al., 2011), which has been found in other studies, mostly among disadvantaged group members (Saguy et al., 2017). Rather, they support evidence that positive contact can foster social change motivation among advantaged (Vezzali et al., 2017) and disadvantaged group members (Kauff et al., 2016). This may be due to contextual factors, for instance, the moderate level of membership salience and the general positive relations between groups of adolescents in our research setting. Similarly, the fact that only perceived legitimacy was associated with social change motivation among advantaged group members, and that perceived stability and permeability were associated with social change motivation in an unpredicted direction among disadvantaged members, may reflect the specific features of our research context and intergroup relations.

These findings help to reconcile the two bodies of literature on intergroup contact and on social change. Despite that the very factors that promote collective action can also disrupt intergroup relations (e.g., ingroup identification, perceived injustice; see Dixon, 2017; van Zomeren et al., 2008; Wright \& Lubensky, 2009), the present study suggests that collective action may also be promoted by maintaining positive relations between groups.

\section{Limitations and Future Research}

A limitation of the current research is its correlational design. Another limitation concerns the sample that consisted only of high school students from a specific geographical location. Furthermore, the number of participants in the immigrant sample was quite low and did not allow the use of SEM analyses with latent variables. Therefore, caution should be taken when interpreting results for this group (see also the relatively low portion of variance explained, $R^{2}=$ .13; see Figure 2).

Our measure of social change may pose an additional limitation, since it measures the motivation for change instead of "real" action. Although this approach to measuring social change is common in literature (see e.g., Çakal et al., 2011; Glasford \& Dovidio, 2011; Tausch et al., 2015), we highlight the need for future research on contact and social change to take into account behavioural measures of social change. Future research should also study different forms of action considering both action intentions and behaviour, as well as aggressive and nonaggressive forms of 
action, as the processes underlying these may be different depending on the sociopolitical context.

We further acknowledge the limitation of our difference-focused contact measure, that assessed both perceptions of differences and of inequalities (see online supplemental material). Although the two aspects are related (note that reliability of the measure is good), they are not the same, and this distinction is especially relevant in light of the other variables we used. As an example, discussions on inequalities may have stronger associations with legitimacy perceptions than discussions regarding differences in general. Future studies should distinguish the two aspects and investigate in detail the role of content of contact in shaping social change motivations.

It should be noted that, according to SIT (see Tajfel, 1981), an alternative prediction could have been made with respect to the role of (il)legitimacy. In fact, when threat (in the case of illegitimacy, threat to the advantaged group's identity as a fair and positive group) is not high, advantaged group members might react to the threat with increased bias (in terms of our study, with reduced social change motivation). In other words, advantaged group members may perceive that the level of illegitimacy is not sufficiently high to threaten their positive self-image as group members and motivate them to address the inequality; in this case, they may perceive illegitimacy of the status relation as a threat to their group position, and react with increased bias (in our case, less motivation to engage in social change). Therefore, there is likely a threshold of the threat to the group image that, if crossed, may lead members to disidentify from their group and/or to take action to restore the positivity of its image (e.g., by supporting social change to the benefit of the disadvantaged group). Unfortunately, in this study there is no way to empirically assess this threshold and whether the association between increased illegitimacy and greater social change motivation may be explained by having crossed it; although note that perceptions of legitimacy in the Italian sample were lower than the midpoint, $t(391)=11.00$, $p<.001, d=0.55$, thus suggesting a moderate to high level of perceived illegitimacy. Future studies should address this key point in order to provide useful indications on the threshold above or below which advantaged group members will start supporting disadvantaged group members' rights, or instead will react to the threat to group image with greater bias (see Schmid, Hewstone, Kupper, Zick, \& Tausch, 2014).

Recent research (e.g., Reimer et al., 2017) highlighted the possibility that negative contact would influence social change motivation. In fact, even if the vast majority of recent research has focused on positive forms of intergroup interactions, also the effects of negative contact on social change should be taken into account. Our research focused on the conditions and mechanisms under which positive contact promotes social change, and did not include measures of negative contact. On the other hand, recent work assessing the relationship of positive and negative contact with collective action (e.g., Hayward et al., 2018; Reimer et al., 2017) did not examine possible moderators. Future studies should, thus, try to disentangle the relation between social change, positive and negative contact, and relevant variables identified by SIT, including the moderating conditions that allow or inhibit the effects of contact on collective action considered in the present research.

Finally, future research should investigate other factors that may contribute to a better understanding of the relations between contact, SIT, and social change. For example, it may be important to explore the role of group representations: it is possible that, when dual identity is salient, contact will stimulate social change (see Ufkes, Calcagno, Glasford, \& Dovidio, 2016). Guilt and threat should also be more carefully considered. For example, guilt could represent another key factor allowing contact to positively ignite support for change among advantaged group members, whilst threat may play a different role, preventing individuals from engaging in social change or promoting more aggressive types of social change. A further variable to consider in future research is group identification. According to SIT, when identification is high, individuals are more likely to opt for group instead of individual strategies (Tajfel \& Turner, 1979). For instance, it 
may be that highly identified individuals from the advantaged group are less sensitive to illegitimacy of status relationships and therefore more resistant to social change. In addition, the role of contact between members of different disadvantaged groups in promoting common social identification, and thus political solidarity and joint collective action, is another potential area for future research (see Dixon et al., 2017).

\section{Conclusion}

Earlier contact theorists were interested not merely in making people from different groups more positive toward one another, but also in how to foster social change, an idea that received less attention in subsequent years (Dixon, 2017). By integrating intergroup contact theory and SIT, our findings provide new insights into the processes driving contact to trigger motivation for social change among both advantaged and disadvantaged groups. We encourage researchers to consider integrating intergroup theories that speak to social change such as SIT and intergroup contact theory, and examine the very conditions that allow maintaining positive relations and, at the same time, promote equality.

\section{Acknowledgements}

We thank Rupert Brown for his precious comments on an earlier version of this manuscript.

\section{Funding}

The author(s) received no financial support for the research, authorship, and/or publication of this article.

\section{ORCID iDs}

Gian Antonio Di Bernardo (iD https://orcid.org/00000002-3922-5712

Loris Vezzali (iD https://orcid.org/0000-0001-75369994

Sofia Stathi (iD) https://orcid.org/0000-0002-12185239

\section{Supplemental material}

Supplemental material for this article is available online.

\section{Note}

1. In addition to the main models, we ran two alternative models, where membership salience or content of contact were not tested as moderators, but (also in light of the correlations emerged; see Table 2) they were instead integrated into the mediation chain (see Table 3). Results revealed indirect effects in the Italian sample for the model where social change motivation and membership salience were tested as mediators in the chain from sociostructural factors to contact: stability and legitimacy $\rightarrow$ social change motivation $\rightarrow$ membership salience $\rightarrow$ contact quantity and quality. Note that, as shown in Table 3, when comparing both main and alternative models using the AIC and CAIC indexes, it emerged that main models showed a better adaptation to the data compared with the other models (for further details, data are available upon request from the corresponding author).

\section{References}

Banfield, J. C., \& Dovidio, J. F. (2013). Whites' perceptions of discrimination against Blacks: The influence of common identity. Journal of Experimental Social Psychology, 49, 833-841. http://doi. org/10.1016/j.jesp.2013.04.008

Becker, J. C., \& Tausch, N. (2015). A dynamic model of engagement in normative and non-normative collective action: Psychological antecedents, consequences, and barriers. European Review of Social Psychology, 26, 43-92. http://doi.org/10.1080/10 463283.2015.1094265

Becker, J. C., Wright, S. C., Lubensky, M. E., \& Zhou, S. (2013). Friend or ally: Whether cross-group contact undermines collective action depends on what advantaged group members say (or don't say). Personality and Social Psychology Bulletin, 39, 442455. http://doi.org/10.1177/0146167213477155

Brown, R., \& Hewstone, M. (2005). An integrative theory of intergroup contact. Advances in Experimental Social Psychology, 37, 255-343. http://doi. org/10.1016/S0065-2601(05)37005-5

Çakal, H., Hewstone, M., Güler, M., \& Heath, A. (2016). Predicting support for collective action in the conflict between Turks and Kurds: Perceived threats as a mediator of intergroup contact and social identity. Group Processes \& Intergroup Relations, 19, 732-752. http://doi. org $/ 10.1177 / 1368430216641303$ 
Çakal, H., Hewstone, M., Schwär, G., \& Heath, A. (2011). An investigation of the social identity model of collective action and the "sedative" effect of intergroup contact among Black and White students in South Africa. British Journal of Social Psychology, 50, 606-627. http://doi. org/10.1111/j.2044-8309.2011.02075.x

Capozza, D., Trifiletti, E., Vezzali, L., \& Favara, I. (2013). Can intergroup contact improve humanity attributions? International Journal of Psychology, 48, 527-541. http://doi.org/10.1080/00207594. 2012.688132

Cohen, J. (1988). Statistical power analysis for the behavioral sciences (2nd ed.). Hillsdale, NJ: Lawrence Erlbaum Associates.

Di Bernardo, G. A., Vezzali, L., Stathi, S., Cadamuro, A., \& Cortesi, L. (2017). Vicarious, extended and imagined intergroup contact: A review of interventions based on indirect contact strategies applied in educational settings. TPM - Testing, Psychometrics, Methodology in Applied Psychology, 24, 3-21. http://doi.org/10.4473/TPM24.1.1

Dixon, J. (2017). Concluding thoughts: The past, present and future of research on the contact hypothesis. In L. Vezzali \& S. Stathi (Eds.), Intergroup contact theory: Recent developments and future directions (pp. 168-184). Abingdon, UK: Routledge.

Dixon, J., Durrheim, K., \& Thomae, M. (2017). The principle-implementation gap in attitudes towards racial equality (and how to close it). Advances in Political Psychology, 38, 91-126. http:/ / doi.org/10.1111/pops.12393

Dixon, J., Durrheim, K., \& Tredoux, C. (2005). Beyond the optimal strategy: A "reality check" for the contact hypothesis. American Psychologist, 60, 697-711. http://doi.org/10.1037/0003-066X.60.7.697

Dixon, J., Durrheim, K., \& Tredoux, C. (2007). Intergroup contact and attitudes toward the principle and practice of racial equality. Psychological Science, 18, 867-872. http://doi.org/10.1111/j.14679280.2007.01993.x

Droogendyk, L., Louis, W. R., \& Wright, S. C. (2016). Renewed promise for positive cross-group contact: The role of supportive contact in empowering collective action. Canadian Journal of Behavioural Science, 48, 317-327. http://doi.org/10.1037/ cbs0000058

Durrheim, K., \& Dixon, J. (2004). Attitudes in the fiber of everyday life: The discourse of racial evaluation and the lived experience of desegregation. American Psychologist, 59, 626-636. http://doi. org/10.1037/0003-066X.59.7.626
Ellemers, N. (1993). The influence of socio-structural variables on identity management strategies. European Review of Social Psychology, 4, 27-57. http://doi. org/10.1080/14792779343000013

Ellemers, N., \& Barreto, M. (2009). Collective action in modern times: How modern expressions of prejudice prevent collective action. Journal of Social Issues, 65, 749-768. http://doi.org/10.1111/ j.1540-4560.2009.01621.x

Ellemers, N., Wilke, H., \& van Knippenberg, A. (1993). Effects of the legitimacy of low group or individual status on individual and collective status-enhancement strategies. Journal of Personality and Social Psychology, 64, 766-778. http://doi. org/10.1037/0022-3514.64.5.766

European Commission. (2018a). Please tell me whether each of the following statements evokes a positive or negative feeling for you. Immigration of people from other $E U$ member states (11/2014) [Data chart]. Retrieved from http:// ec.europa.eu/commfrontoffice/publicopinion/index.cfm/Chart/getChart/themeKy/59/ groupKy/278

European Commission. (2018b). Please tell me whether each of the following statements evokes a positive or negative feeling for you. Immigration of people from outside the $E U$ (11/2014) [Data chart]. Retrieved from http:// ec.europa.eu/commfrontoffice/publicopinion/index.cfm/Chart/getChart/themeKy/59/ groupKy/279

Fritz, M. S., \& MacKinnon, D. P. (2007). Required sample size to detect the mediated effect. Psychological Science, 18, 233-239. http://doi.org/10.1111/ j.1467-9280.2007.01882.x

Glasford, D. E., \& Calcagno, J. (2012). The conflict of harmony: Intergroup contact, commonality and political solidarity between minority groups. Journal of Experimental Social Psychology, 48, 323-328. http://doi.org/10.1016/j. jesp.2011.10.001

Glasford, D. E., \& Dovidio, J. F. (2011). E pluribus unum: Dual identity and minority group members' motivation to engage in contact, as well as social change. Journal of Experimental Social Psychology, 47, 1021-1024. http://doi.org/10.1016/j. jesp.2011.03.021

Glasford, D. E., \& Johnston, B. (2018). Respect the technique: Status-based respect increases minority group social cohesion with majority groups, while also increasing minority collective action tendencies. Journal of Social Psychology, 158, 201214. http://doi.org/10.1080/00224545.2017.13 24395 
Greenland, K., \& Brown, R. (1999). Categorization and intergroup anxiety in contact between British and Japanese nationals. European Journal of Social Psychology, 29, 503-521. http://doi.org/10.1002/ (SICI) 1099-0992(199906)29:4< 503::AIDEJSP941>3.0.CO;2-Y

Harwood, J., Hewstone, M., Paolini, S., \& Voci, A. (2005). Grandparent-grandchild contact and attitudes toward older adults: Moderator and mediator effects. Personality and Social Psychology Bulletin, 31, 393-406. http://doi. org $/ 10.1177 / 0146167204271577$

Hau, K. T., \& Marsh, H. W. (2004). The use of item parcels in structural equation modelling: Non-normal data and small sample sizes. British Journal of Mathematical and Statistical Psychology, 57, 327-351. http:// doi.org/10.1111/j.2044-8317.2004.tb00142.x

Hays, N. A., \& Blader, S. L. (2017). To give or not to give? Interactive effects of status and legitimacy on generosity. Journal of Personality and Social Psychology, 112, 17-38. http://doi.org/10.1037/ pspi0000067

Hayward, L. E., Tropp, L. R., Hornsey, M. J., \& Barlow, F. K. (2018). How negative contact and positive contact with Whites predict collective action among racial and ethnic minorities. British Journal of Social Psychology, 57, 1-20. http://doi. org $/ 10.1111 /$ bjso.12220

Her, Y. W., Shin, H., \& Pae, S. (2018). A multigroup SEM analysis of moderating role of task uncertainty on budgetary participation-performance relationship: Evidence from Korea. Asia Pacific Management Review. Advance online publication. http://doi.org/10.1016/j.apmrv.2018.02.001

Hodson, G., \& Hewstone, M. (2013). Advances in intergroup contact. Hove, UK: Psychology Press.

Iacobucci, D., Posavac, S. S., Kardes, F. R., Schneider, M. J., \& Popovich, D. L. (2015). The median split: Robust, refined, and revived. Journal of Consumer Psychology, 25, 690-704. http://doi.org/10.1016/j. jcps.2015.06.014

Italian National Institute of Statistics. (2015). La povertà in Italia [Poverty in Italy]. Retrieved from http:// sociale.regione.emilia-romagna.it/documentazione/pubblicazioni/ricerche-e-statistiche/la-poverta-in-italia-1

Iyer, A., Leach, C. W., \& Crosby, F. J. (2003). White guilt and racial compensation: The benefits and limits of self-focus. Personality and Social Psychology Bulletin, 29, 117-129. http://doi. org/10.1177/0146167202238377
Jackman, M. R., \& Crane, M. (1986). "Some of my best friends are Black. . .": Interracial friendship and Whites' racial attitudes. Public Opinion Quarterly, 50, 459-486. http://doi.org/10.1086/268998

Jetten, J., Spears, R., \& Postmes, T. (2004). Intergroup distinctiveness and differentiation: A meta-analytic integration. Journal of Personality and Social Psychology, 86, 862-879. http://doi. org/10.1037/0022-3514.86.6.862

Kauff, M., Green, E. G. T., Schmid, K., Hewstone, M., \& Christ, O. (2016). Effects of majority members' positive intergroup contact on minority members' support for ingroup rights: Mobilizing or demobilizing effects? European Journal of Social Psychology, 46, 833-839. http://doi.org/10.1002/ejsp.2194

Lickel, B., Schmader, T., \& Barquissau, M. (2004). The evocation of moral emotions in intergroup contexts: The distinction between collective guilt and collective shame. In N. R. Branscombe \& B. Doosje (Eds.), Collective guilt: International perspectives (pp. 35-55). New York, NY: Cambridge University Press.

Little, T. D., Cunningham, W. A., Shahar, G., \& Widaman, K. F. (2002). To parcel or not to parcel: Exploring the question, weighing the merits. Structural Equation Modeling, 9, 151-173. http:// doi.org/10.1207/S15328007SEM0902_1

Major, B., Gramzow, R. H., McCoy, S. K., Levin, S., Schmader, T., \& Sidanius, J. (2002). Perceiving personal discrimination: The role of group status and legitimizing ideology. Journal of Personality and Social Psychology, 82, 269-282. http://doi. org/10.1037/0022-3514.82.3.269

McKeown, S., \& Dixon, J. (2017). The "contact hypothesis": Critical reflections and future directions. Social and Personality Psychology Compass, 11. http://doi.org/10.1111/spc3.12295

McKeown, S., \& Taylor, L. K. (2017). Intergroup contact and peacebuilding: Promoting youth civic engagement in Northern Ireland. Social and Personality Psychology Compass, 11. http://doi. org/10.1111/spc3.12295

Miron, A. M., Branscombe, N. R., \& Schmitt, M. T. (2006). Collective guilt as distress over illegitimate intergroup inequality. Group Processes \& Intergroup Relations, 9, 163-180. http://doi. org/10.1177/1368430206062075

Mummendey, A., Klink, A., Mielke, R., Wenzel, M., \& Blanz, M. (1999). Socio-structural characteristics of intergroup relations and identity management strategies: Results from a field study 
in East Germany. European Journal of Social Psychology, 29, 259-285. http://doi.org/10.1002/ (SICI) 1099-0992(199903/05)29:2/3<259::AIDEJSP927>3.0.CO;2-

Pettigrew, T. F., \& Tropp, L. R. (2006). A meta-analytic test of intergroup contact theory. Journal of Personality and Social Psychology, 90, 751-783. http://doi.org/10.1037/0022-3514.90.5.7510223514.90.5.751

Pettigrew, T. F., \& Tropp, L. R. (2011). When groups meet: The dynamics of intergroup contact. New York, NY: Psychology Press.

Pew Research Center. (2007). World publics welcome global trade - But not immigration: 47-nation Pew Global Attitudes Survey. Retrieved from http://www.pewglobal.org/2007/10/04/

Poore, A. G., Gagne, F., Barlow, K. M., Lydon, J. E., Taylor, D. M., \& Wright, S. C. (2002). Contact and the person/group discrimination discrepancy in an Inuit community. Journal of Psychology, 136, 371-382. http://doi.org/10.1080 /00223980209604164

Regione Emilia-Romagna. (2017). Cittadini stranieri in Emilia-Romagna. Percorsi scolastici, formativi e universitari. Anno 2017 [Foreign citizens in EmiliaRomagna. Schooling, training, and university. Year 2017]. Retrieved from https://sociale. regione.emilia-romagna.it/immigrati-e-stranieri/ temi/osservatorio-regionale-sul-fenomeno-migratorio/focus-n-3-percorsi-scolastici-formativi-euniversitari-cittadini-stranieri-dati-2016-17

Reimer, N. K., Becker, J. C., Benz, A., Christ, O., Dhont, K., Klocke, U., . . Hewstone, M. (2017). Intergroup contact and social change: Implications of negative and positive contact for collective action in advantaged and disadvantaged groups. Personality and Social Psychology Bulletin, 43, 121-136. http://doi.org/10.1177/0146167216676478

Saguy, T. (2018). Downside of intergroup harmony? When reconciliation might backfire and what to do. Policy Insights from the Behavioral and Brain Sciences, 5, 75-81. http://doi. org/10.1177/2372732217747085

Saguy, T., \& Chernyak-Hai, L. (2012). Intergroup contact can undermine disadvantaged group members' attributions to discrimination. Journal of Experimental Social Psychology, 48, 714-720. http:// doi.org/10.1016/j.jesp.2012.01.003

Saguy, T., \& Dovidio, J. F. (2013). Insecure status relations shape preferences for the content of intergroup contact. Personality and Social
Psychology Bulletin, 39, 1030-1042. http://doi. org $/ 10.1177 / 0146167213487078$

Saguy, T., Dovidio, J. F., \& Pratto, F. (2008). Beyond contact: Intergroup contact in the context of power relations. Personality and Social Psychology Bulletin, 34, 432-445. http://doi. org/10.1177/0146167207311200

Saguy, T., Shchory-Eyal, N., Hasan-Aslih, S., Sobol, D., \& Dovidio, J. F. (2017). The irony of harmony: Past and new developments. In L. Vezzali \& S. Stathi (Eds.), Intergroup contact theory: Recent developments and future directions (pp. 53-71). Abingdon, UK: Routledge.

Saguy, T., Tausch, N., Dovidio, J. F., \& Pratto, F. (2009). The irony of harmony: Intergroup contact can produce false expectations for equality. Psychological Science, 20, 114-121. http://doi. org/10.1111/j.1467-9280.2008.02261.x

Scheepers, D., \& Ellemers, N. (2005). When the pressure is up: The assessment of social identity threat in low and high status groups. Journal of Experimental Social Psychology, 41, 192-200. http://doi. org/10.1016/j.jesp.2004.06.002

Scheepers, D., Röell, C., \& Ellemers, N. (2015). Unstable power threatens the powerful and challenges the powerless: Evidence from cardiovascular markers of motivation. Frontiers in Psychology, 6. http://doi.org/10.3389/fpsyg.2015.00720

Scheepers, D., Spears, R., Doosje, B., \& Manstead, A. S. R. (2006). The social functions of ingroup bias: Creating, confirming, or changing social reality. European Review of Social Psychology, 17, 359-396. http://doi.org/10.1080/10463280601088773

Schmid, K., Hewstone, M., Kupper, B., Zick, A., \& Tausch, N. (2014). Reducing aggressive intergroup action tendencies: Effects of intergroup contact via perceived intergroup threat. Aggressive Behaviour, 40, 250-262. http://doi.org/10.1002/ jts5.15

Selvanathan, H. P., Techakesari, P., Tropp, L. R., \& Barlow, F. K. (2017). Whites for racial justice: How contact with Black Americans predicts support for collective action among White Americans. Group Processes \& Intergroup Relations. Advance online publication. http://doi. org/10.1177/1368430217690908

Sengupta, N. K., \& Sibley, C. G. (2013). Perpetuating one's own disadvantage: Intergroup contact enables the ideological legitimation of inequality. Personality and Social Psychology Bulletin, 39, 1391-1403. http://doi.org/10.1177/0146167213497593 
Simon, B., \& Klandermans, B. (2001). Politicized collective identity: A social psychological analysis. American Psychologist, 56, 319-331. http://doi. org/10.1037/0003-066X.56.4.319

Stewart, T., Latu, I. M., Branscombe, N. R., \& Denney, H. T. (2010). Yes we can! Prejudice reduction through seeing (inequality) and believing (in social change). Psychological Science, 21, 1557-1562. http://doi.org/10.1177/0956797610385354

Stürmer, S., \& Simon, B. (2004). The role of collective identification in social movement participation: A panel study in the context of the German gay movement. Personality and Social Psychology Bulletin, 30, 263-277. http://doi. org $/ 10.1177 / 0146167203256690$

Sweetman, J., Spears, R., Livingstone, A. G., \& Manstead, A. S. R. (2013). Admiration regulates social hierarchy: Antecedents, dispositions, and effects on intergroup behavior. Journal of Experimental Social Psychology, 49, 534-542. http://doi. org/10.1016/j.jesp.2012.10.007

Swim, J. K., \& Miller, D. L. (1999). White guilt: Its antecedents and consequences for attitudes toward affirmative action. Personality and Social Psychology Bulletin, 25, 500-514. http://doi. org $/ 10.1177 / 0146167299025004008$

Tajfel, H. (1978). Differentiation between social groups: Studies in the social psychology of intergroup relations. London, UK: Academic Press.

Tajfel, H. (1981). Human groups and social categories. Cambridge, UK: Cambridge University Press.

Tajfel, H., \& Turner, J. C. (1979). An integrative theory of intergroup conflicts. In W. G. Austin \& S. Worchel (Eds.), The social psychology of intergroup relations (pp. 33-47). Monterey, CA: Brooks-Cole.

Tausch, N., Saguy, T., \& Bryson, J. (2015). How does intergroup contact affect social change? Its impact on collective action and individual mobility intentions among members of a disadvantaged group. Journal of Social Issues, 71, 536-553. http:// doi.org/10.1111/josi.12127

Tropp, L. R., Hawi, D. R., van Laar, C., \& Levin, S. (2012). Cross-ethnic friendships, perceived discrimination, and their effects on ethnic activism over time: A longitudinal investigation of three ethnic minority groups. British Journal of Social Psychology, 51, 257-272. http://doi.org/10.1111/ j.2044-8309.2011.02050.x

Tropp, L. R., \& Pettigrew, T. F. (2005). Relationships between intergroup contact and prejudice among minority and majority status groups. Psychological
Science, 16, 951-957. http://doi.org/10.1111/ j.1467-9280.2005.01643.x

Turner, J. C., \& Brown, R. (1978). Social status, cognitive alternatives, and intergroup relations. In H. Tajfel (Ed.), Differentiation between social groups: Studies in the social psychology of intergroup relations (pp. 201-234). London, UK: Academic Press.

Ufkes, E. G., Calcagno, J., Glasford, D. E., \& Dovidio, J. F. (2016). Understanding how common ingroup identity undermines collective action among disadvantaged-group members. Journal of Experimental Social Psychology, 63, 26-35. http:// doi.org/10.1016/j.jesp.2015.11.006

Van Zomeren, M., Leach, C. W., \& Spears, R. (2012). Protesters as "passionate economists": A dynamic dual pathway model of approach coping with collective disadvantage. Personality and Social Psychology Review, 16, 180-199. http://doi. org $/ 10.1177 / 1088868311430835$

Van Zomeren, M., Postmes, T., \& Spears, R. (2008). Toward an integrative social identity model of collective action: A quantitative research synthesis of three socio-psychological perspectives. Psychological Bulletin, 134, 504-535. http://doi. org/10.1037/0033-2909.134.4.504

Van Zomeren, M., Spears, R., Fischer, A. H., \& Leach, C. W. (2004). Put your money where your mouth is! Explaining collective action tendencies through group-based anger and group efficacy. Journal of Personality and Social Psychology, 87, 649664. http://doi.org/10.1037/0022-3514.87.5.649

Vezzali, L., Andrighetto, L., Capozza, D., Di Bernardo, G. A., \& Saguy, T. (2017). Discussing differences between groups: The content of intergroup encounters and motivation for social change among members of advantaged groups. Journal of Theoretical Social Psychology. Advance online publication. http://doi.org/10.1002/jts5.12

Vezzali, L., Cadamuro, A., Versari, A., Giovannini, D., \& Trifiletti, E. (2015). Feeling like a group after a natural disaster: Common ingroup identity and relations with outgroup victims among majority and minority young children. British Journal of Social Psychology, 54, 519-538. http://doi.org/10.1111/bjso.12091

Vezzali, L., \& Capozza, D. (2011). Reducing explicit and implicit prejudice toward disabled colleagues: Effects of contact and membership salience in the workplace. Life Span and Disability, 14, 139-162.

Vezzali, L., \& Giovannini, D. (2011). Intergroup contact and reduction of explicit and implicit prejudice towards immigrants: A study with Italian 
businessmen owning small and medium enterprises. Quality and Quantity, 45, 213-222. http:// doi.org/10.1007/s11135-010-9366-0

Vezzali, L., Giovannini, D., \& Capozza, D. (2010). Longitudinal effects of contact on intergroup relations: The role of majority and minority group membership and intergroup emotions. Journal of Community and Applied Social Psychology, 20, 462479. http://doi.org/10.1002/casp.1058

Vezzali, L., Stathi, S., \& Giovannini, D. (2012). Indirect contact through book reading: Improving adolescents' attitudes and behavioral intentions toward immigrants. Psychology in the Schools, 49, 148-162. http://doi.org/10.1002/pits.20621

Voci, A., \& Hewstone, M. (2003). Intergroup contact and prejudice toward immigrants in Italy: The mediational role of anxiety and the moderational role of group salience. Group Processes \& Intergroup Relations, 6, 37-54. http://doi. org/10.1177/1368430203006001011
Vorauer, J. D., \& Sakamoto, Y. (2008). Who cares what the outgroup thinks? Testing an information search model of the importance individuals accord to an outgroup member's view of them during intergroup interaction. Journal of Personality and Social Psychology, 95, 1467-1480. http://doi. org/10.1037/a0012631

Wellman, J. D., Liu, X., \& Wilkins, C. L. (2016). Priming status-legitimizing beliefs: Examining the impact on perceived anti-White bias, zerosum beliefs, and support for affirmative action among White people. British Journal of Social Psychology, 55, 426-437. http://doi.org/10.1111/ bjso. 12133

Wright, S. C., \& Lubensky, M. E. (2009). The struggle for social equality: Collective action versus prejudice reduction. In S. Demoulin, J. P. Leyens, \& J. F. Dovidio (Eds.), Intergroup misunderstandings: Impact of divergent social realities (pp. 291-310). New York, NY: Psychology Press. 